\title{
Comparative Assessment of the Yields of Silica from Husk Ashes of Digitaria exilis (acha), wheat and rice.
}

\author{
${ }^{1}$ Shamle, N.J.*, ${ }^{1}$ Dados, C.J., ${ }^{1}$ Iwoh, S.E., ${ }^{2}$ Nangbes, J.G. and \\ ${ }^{1}$ Awode, A.U. \\ ${ }^{1}$ (Department of Chemistry, University of Jos, Nigeria) \\ 2 (Plateau State University Bokkos, Plateau State, Nigeria)
}

\begin{abstract}
The isolation of amorphous silica from acha husk ash (AHA), wheat husk ash (WHA) and rice husk ash (RHA) was carried out in this work. The different husk ashes were obtained by the calcination of the respective husks in a muffle furnace at $500^{\circ} \mathrm{C}$ for five hours. Silica was extracted as sodium silicate from the respective ashes using $\mathrm{NaOH}$ solution. A solution of $\mathrm{HCl}$ was added to the sodium silicate to lower the $\mathrm{pH}$ to 7.0 to produce silica aquagels which were subsequently dried to give silica xerogels. The mineral contents of the xerogels, AHA, WHA and RHA were determined by energy dispersive $x$-ray fluorescence spectroscopy (ED$X R F$, Model PW 4025/45B). The percentage of silica in the AHA, WHA and RHA were $(57.50 \pm 1.10) \%$, $(59.68 \pm 1.10) \%$ and $(68.50 \pm 0.20) \%$ respectively, while the silica content of the respective xerogels were $(92.03 \pm 0.82) \%,(88.43 \pm 2.13) \%$ and $(88.55 \pm 0.20) \%$. The results distinguish AHA as an effective alternative source of silica, having the highest yield with minimal mineral contaminants.
\end{abstract}

Keywords: Digitaria exillis, husk ashes, amorphous silica, aquagel, xerogel.

\section{Introduction}

Digitaria spp. ("acha") also known as hungry rice or fonio is probably the oldest African cereal crop. It is indigenous to West Africa where it is grown for its edible grains and its straws [1]. "Acha" grain is surrounded by an outer protective covering (husk, hull or glume) similar to that of rice from which acha husk is obtained [2]. The acha husk ash (AHA), a non-pozzolonic material with specific gravity value of 2.12 is produced by the calcination of the husk [3].

On the other hand, wheat (triticum spp) is the common name for members of genus triticum of the grass family (poa ceae). The wheat kernel consists of a husk and seed. The total volume of the husk stands for approximately $5 \%$ of the kernel [4]. The husk is made up of liguin (16.4\%), cellulose (30.5\%), hemi cellulose (28.9\%), ash content (16.6\%) and others [5]. When the husk is burnt, it produces wheat husk ash (WHA) which has high silica content. Similarly, rice (oryza sativa L.) is one of the leading food crops produced in all the continents of the world. Rice husk is an agro-waste produced in hundred millions of tons. In Nigeria, about 2 million tons of rice is produced annually [6]. Rice husk ash (RHA) which is obtained by burning rice husk can be of economic value as raw material for the manufacture of silica based products [7]. It contains about $60 \%$ silica [8], [9], [10].

Silica has been widely used in pharmaceutical products, chromatograph column packing, detergents, adhesives, electronics, dental material, ceramic and as adsorbent [11], [12], [13]. Silica has also been used as a major precursor for a number of inorganic and organometallic materials which have applications in synthetic chemistry as catalysts and in thin films or coatings for electronic and optical materials [11], [14]. Farook et al. [15] reported the use of amorphous silica produced from RHA as an inert support material with a large surface area where any metal or its oxide can be chemically incorporated and dispersed throughout the matrix.

This paper attempts to compare the yields of amorphous silica isolated from the ashes of three agrowaste products; acha husk, wheat husk and rice husk in order to determine the place of acha (digitaria spp.) husk among other cereals husk as potential source of silica. Hitherto, acha husk has been dumped or burnt to ashes which constitute environmental pollution challenges. On the other hand, previous studies have been carried out extensively on WHA and RHA using different methods; they are therefore studied together to guide in this assessment. This work employs the method of Kalapathy et al. [7] for the silica extraction. This process has dual benefits; production of valuable silica particles at lower cost with reduction in waste disposal as well as ash pollution challenges.

\subsection{Sample Preparation}

\section{Experimental}

Acha husk, wheat husk and rice husk obtained from local milling companies were first of all washed thoroughly with deionized water to remove the adhering soil and dust particles. They were then dried under 
sunlight for 48 hours. The dried husks were ground into powder and sieved through $20 \mu \mathrm{m}$ mesh size. The powder from the respective husks were then oxidized in a muffle furnace at $500^{\circ} \mathrm{C}$ for 5 hours to produce white ashes. The respective ashes designated as AHA, WHA and RHA were stirred in $1.0 \mathrm{M} \mathrm{HNO}_{3}$ for 24 hours and washed thoroughly with distilled water.

\subsection{Silica Extraction}

Silica was extracted from the husk ashes adapting the method of Kamath and Proctor [8]. Sixty ml portions of $1 \mathrm{M} \mathrm{NaOH}$ were added to the washed AHA, WHA and RHA samples and boiled in covered $250 \mathrm{ml}$ Erlenmeyer flasks for 1 hour with constant stirring to dissolve the silica and produce a sodium silicate solution. The solutions were filtered through Whatman No. 41 ashless filter paper, and the carbon residues were washed with $100 \mathrm{ml}$ of boiling water. The filtrates and washings were allowed to cool to room temperature and then titrated with $1 \mathrm{M} \mathrm{HCl}$ with constant stirring to $\mathrm{pH} 7$. Silica gels started to precipitate when the $\mathrm{pH}$ decreased to $<10$. The gels were aged for 18 hours. Deionized water $(100 \mathrm{ml})$ was added to the gels and they were broken to make slurry. The slurries were then centrifuged for 15 minutes at $4000 \mathrm{rpm}$, the clear supernatants were discarded and the washing step repeated. The gels (aquagels) were transferred into beakers and dried at $80^{\circ} \mathrm{C}$ for 12 hours to produce xerogels. All the samples were stored in airtight plastic bottles. A flow diagram of the procedure is shown in fig. 1.

\subsection{Moisture Content of Silica Gels}

Moisture content of the silica gels was determined using an air oven method (AOAC, 1990). About $0.5 \mathrm{~g}$ portions of each sample was placed in pre-heated and weighed petri-dish. They were heated in a hot air oven at $130^{\circ} \mathrm{C}$ for 1 hour. The samples were cooled in a dessicator and weighed. The loss in weight was recorded as the moisture content of the samples.

\subsection{Chemical Analysis}

Silica $\left(\mathrm{SiO}_{2}\right)$ and other elemental oxides content of the AHA, WHA, RHA and their respective xerogels were determined using energy dispersive x-ray fluorescence (ED-XRF model PW 4025/45B). XRF spectroscopy is widely used for qualitative and quantitative elemental analysis of samples because of its advantage of being non-destructive, multi-elemental detection, fast analysis and cost effective. Since this technique determines the elemental content of the surface of the silica particles, the samples were finely ground to minimize the possible effect of non-uniform distribution of elements inside the silica particles. Ground silica samples were dried at $130^{\circ} \mathrm{C}$ for 2 hours and stored under nitrogen. Samples were loaded into the vacuum sampling chamber of the ED-XRF and analyzed.

Dispersed $\mathrm{X}^{\mathrm{a}} \mathrm{HA}$ in $1 \mathrm{~m} \mathrm{NaOH}(60 \mathrm{ml})$ 


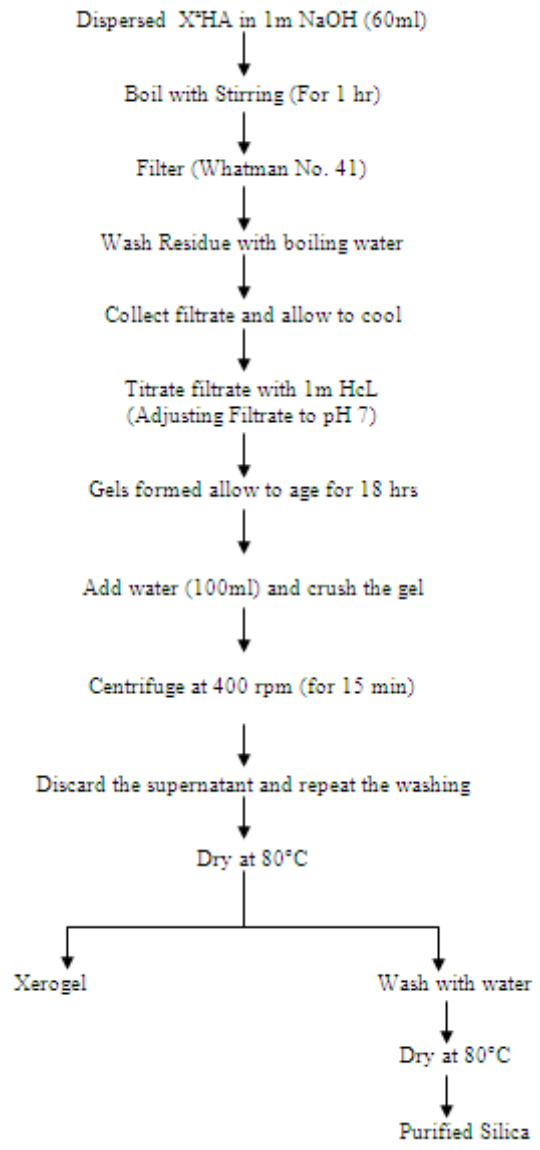

a. X in XHA above represents W, R and A for WHA, RHA and AHA respectively.

Fig. 1: Flow diagram of the procedure used to extract silica from AHA, WHA and RHA.

\section{Results And Discussion}

The moisture content for silica xerogels isolated from AHA, WHA and RHA were found to be $3.06 \mathrm{wt}$ $\%, 1.53 \mathrm{wt} \%$ and $3.40 \mathrm{wt} \%$ respectively. The chemical composition of the ashes and their respective xerogels are presented in Table 1. The content of silica in AHA, WHA and RHA were $57.50 \mathrm{wt} \%, 59.68 \mathrm{wt} \%$ and $68.50 \%$ wt $\%$ respectively. The main impurities of WHA were $\mathrm{K}_{2} \mathrm{O}, \mathrm{CaO}$ and $\mathrm{P}_{2} \mathrm{O}_{5}(16.33 \mathrm{qt} \%, 9.54$ wt $\%$ and $5.37 \mathrm{wt} \%$ respectively); for RHA the impurities were $\mathrm{P}_{2} \mathrm{O}_{5}$ and $\mathrm{K}_{2} \mathrm{O}(12.70 \mathrm{wt} \%)$ and $\left.6.40 \mathrm{wt} \%\right)$ and for AHA the impurities were $\mathrm{K}_{2} \mathrm{O}, \mathrm{P}_{2} \mathrm{O}_{5}$ and $\mathrm{CaO}(12.13 \mathrm{wt} \%, 11.85 \mathrm{wt} \%$ and $9.16 \mathrm{wt} \%$ respectively). These major impurities were leached out when the ashes were treated with $1.0 \mathrm{M} \mathrm{HNO}_{3}$ solution for 24 hours and washed. The silica content of the xerogels from AHA, WHA and RHA were 92.03 wt $\%, 88.43$ wt $\%$ and 84.45 wt $\%$ respectively. All the three silica xerogels have chlorine ( $5.54 \mathrm{wt} \%, 9.36 \mathrm{wt} \%$ and $12.10 \mathrm{wt} \%$ respectively) as their major contaminant. This element was not detected in the ashes. The high content of chlorine in the xerogels was due to the very rapid gelation at $\mathrm{pH} 7.0$ which effectively trapped sodium chloride in the gel matrix [17]. The gelation process is much slower at $\mathrm{pH}<7$ and hence chlorine ions may diffuse out of the gel matrix and can be washed out easily to produce a high purity silica.

Table 1: The Compositional Analysis of AHA, WHA, RHA and those of the respective Silica Xerogels obtained from each.

\begin{tabular}{|c|c|c|c|c|c|c|}
\hline \multirow{2}{*}{$\begin{array}{l}\text { Component } \\
\text { b }\end{array}$} & \multicolumn{6}{|c|}{ Weight \% } \\
\hline & AHA & $\begin{array}{l}\text { Silica Xerogel } \\
\text { from AHA }\end{array}$ & WHA & $\begin{array}{l}\text { Silica Xerogel } \\
\text { from WHA }\end{array}$ & RHA & $\begin{array}{l}\text { Silica Xerogel } \\
\text { from RHA }\end{array}$ \\
\hline $\mathrm{SiO}_{2}$ & 57.50 & 92.03 & 59.68 & 88.43 & 68.50 & 84.45 \\
\hline $\mathrm{MgO}$ & 2.93 & ND & 2.00 & ND & 2.00 & ND \\
\hline $\mathrm{P}_{2} \mathrm{O}_{5}$ & 11.85 & ND & 5.37 & ND & 12.70 & ND \\
\hline $\mathrm{K}_{2} \mathrm{O}$ & 12.13 & 0.61 & 16.33 & 1.09 & 6.40 & 0.40 \\
\hline $\mathrm{CaO}$ & 9.16 & 0.33 & 9.54 & 0.31 & 3.33 & 0.92 \\
\hline $\mathrm{TiO}_{2}$ & 0.19 & 0.03 & 0.10 & 0.03 & 0.23 & 0.08 \\
\hline $\mathrm{V}_{2} \mathrm{O}_{5}$ & 0.04 & ND & & & 0.01 & ND \\
\hline $\mathrm{Cr}_{2} \mathrm{O}_{3}$ & & & & & 0.02 & 0.03 \\
\hline $\mathrm{MnO}$ & 0.66 & 0.02 & 0.37 & 0.02 & 0.68 & 0.03 \\
\hline $\mathrm{Fe}_{2} \mathrm{O}_{3}$ & 1.43 & 0.11 & 0.84 & 0.13 & 2.42 & 0.22 \\
\hline
\end{tabular}


Comparative Assessment of the Yields of Silica from Husk Ashes of Digitaria exillis (acha), wheat ....

\begin{tabular}{llllllc}
$\mathrm{NiO}$ & 0.01 & 0.01 & 0.01 & 0.01 & 0.01 & 0.01 \\
$\mathrm{CuO}$ & 0.10 & 0.03 & 0.08 & 0.06 & 0.07 & 0.04 \\
$\mathrm{ZnO}$ & 0.19 & 0.03 & 0.08 & 0.01 & 0.13 & 0.02 \\
$\mathrm{Cl}$ & $\mathrm{ND}$ & 5.54 & $\mathrm{ND}$ & 9.36 & $\mathrm{ND}$ & 12.10 \\
$\mathrm{Rb} 2 \mathrm{O}$ & & & 0.06 & $\mathrm{ND}$ & & \\
$\mathrm{SrO}$ & & 0.06 & $\mathrm{ND}$ & \\
$\mathrm{BaO}$ & 0.21 & $\mathrm{ND}$ & 0.06 & $\mathrm{ND}$ & \\
$\mathrm{Re}_{2} \mathrm{O}_{7}$ & & & 0.24 & $\mathrm{ND}$ & \\
$\mathrm{CeO}_{2}$ & & & 0.04 & 0.04 & \\
$\mathrm{SO}_{3}$ & 0.99 & $\mathrm{ND}$ & 2.68 & $\mathrm{ND}$ & & \\
\hline
\end{tabular}

b. All the values in table are mean of triplicate readings

\section{Conclusions}

The performance of "acha" (digitaria exilis) husk ash as a potential source of amorphous silica is examined. From the foregoing discussions, it can be inferred that out of the three agro-waste products being investigated, acha husk ash which gave the highest yield with minimal mineral contaminants is an effective source of silica. This revelation does not only increase the options of raw materials for silica production but also takes care of the pollution challenges presented by the dumping of acha husk or its ash in the environment.

\section{References}

[1]. C.A. Echendu, I.C., Obizoba, J.U. Anyika and P.C. Ojimelukwe, changes in chemical composition of treated and untreated Hungry Rice "Acha" (Digitaria exilis), Pakistan Journal of Nutrition, 8, 2009, 17791785.

[2]. D.W. Irving and I.A. Jedeani, Micro structural and composition of D. exilis (Acha), a potential crop, Cereal Chem., 74(3), 1997, 224-228.

[3]. M. Joel, A Review of the partial replacement of element with Agro-waste, University of Agriculture, Civil Eng. Department, P.M.B. 2373 Makurdi, Nigeria, 2010.

[4]. P. Terzioglu and S. Yucel, Synthesis of Magnesium Silicate from wheat husk ash; effects of parameters on structural and surface properties, Bio-resources, 7(4), 2002, 5435-5447.

[5]. M.S. Sobhy and M.T. Tamman, The influence of fiber length and concentration on the physical properties of wheat husk fibre rubber composites, International Journal of Polymer Science, 2010, 2010.

[6]. E.B. Oyetola and M. Abdullahi, The use of Rice husk ash in low-cost Sandcrete block production, Int. Journal of Applied Science, $5,2006,345-351$.

[7]. U. Kalapathy, A. Proctor and J. Shultz, A simple method for production of pure silica from Rice hull ash, Biores. Technol. 73, 2000a, 257-262.

[8]. S.R. Kamath and A. Proctor, Silica gel from Rice hull ash; preparation and characterization, Cereal Chem., 75, 1998, $484-487$.

[9]. R.V. Krishnaro and M.M. Godkhindi, Maximization of SiC whiskers during the pryolysis of burnt Rice husk, Journal Mater. Sei., 27, 1992, 1227-1230.

[10]. T.C. Luan and T.C. Chou, Recovering of silica from the gasification of Rice husk/coal in the presence of a pilit frame in a modified fluidized bed, Ind. Eng. Chem. Res., 29, 1990 1922-1927.

[11]. C.J. Brinker and G.W. Scherer, Applications in Sol-Gel Science, "The Physics and Chemistry of Sol-Gel processing, Academic Press, Inc. San Diego, CA, 1990, 839-880.

[12]. A. Proctor, P.K. Clark and C.A. Parker, Rice hull ash absorbent performance under commercial soy oil bleaching conditions, J.AOCS, 782, 1995, 459-462.

[13]. L. Sun and K. Gong, Review, Silicon-based materials from Rice husk and their application Ind. Eng. Res. 40, $2001,5861-55877$.

[14]. P.W. Lender and R. Ruiter, Novel inorganic materials and heterogeneous catalysis, In: Sheats, J.E., Carraher, C.E., Pittman, C.U., Eldin, M., Currell, B. (Eds), Inorganic and Metal-containing polymeric materials. Plenum Press, New York, NY, 1990, $187-195$.

[15]. A. Farook, B. Saraswathy and W. Phee-Lee, Rice husk ash silica as a support material for ruthernium based heterogeneous catalyst, Journal of Physical Science, 17(2), 2006, 1-13.

[16]. AOAC, Official methods of analysis, Association of Analytical Chemists, Washington DC, $5^{\text {th }}$ ed. 1990

[17]. U. Kalapathy, A. Proctor, and J. Shultz, An improved method for production of silica from Rice hull ash, Bioresource Technology, $85,2002,285-289$ 